\title{
Article
}

Arq Neuropsiquiatr 2011;69(6):900-904

\section{Quality of life in individuals with cervical dystonia before botulinum toxin injection in a Brazilian tertiary care hospital}

\author{
Mariana Ribeiro Queiroz' ${ }^{1}$ Hsin Fen Chien², Egberto Reis Barbosa²
}

\begin{abstract}
Objective: The purpose of this study was to evaluate quality of life (QoL) in a Brazilian population of individuals with cervical dystonia (CD) without effect of botulinum toxin (BTx) or with only residual effect of $\mathrm{BTX}$, and identify possible physical and social aspects that affect their QoL. Method: Sixty five out of sixty seven consecutive patients with CD were assessed with two instruments: Short-form Health Survey with 36 questions (SF-36) and Toronto Western Spasmodic Torticollis Rating Scale (TWSTRS). Results: Severity of CD (TWSTRS) correlated moderately with two SF-36 subscale: role-physical $(r=-0.42)$ and body pain $(r=-0.43)$. Women also scored worse in two subscale of SF-36: vitality $(p<0.05)$ and mental-health $(p<0.005)$. Conclusion: Severity of CD and gender (female) were the main factors related to a worse QoL perception. These findings may help health professionals to predict which characteristics could lead to worse QoL, and therefore, better target their interventions to lessen the burden caused by CD.
\end{abstract}

Key words: cervical dystonia, quality of life, botulinum neurotoxin type-A, Toronto Western Spasmodic Torticollis Rating Scale, Short-form Health Survey.

Qualidade de vida em indivíduos com distonia cervical antes da aplicação de toxina botulínica em um hospital terciário brasileiro

\section{RESUMO}

Objetivo: $O$ objetivo deste estudo foi avaliar a qualidade de vida (QV) em uma população brasileira de indivíduos com distonia cervical (DC), que estavam sem o efeito da toxina botulínica ou com efeito residual da mesma, e identificar os possíveis aspectos físicos e sociais que afetam sua QV. Método: Sessenta e cinco de sessenta e sete pacientes consecutivos com DC foram avaliados com dois instrumentos: Short-form Health Survey com 36 questões (SF-36) e Toronto Western Spasmodic Torticollis Rating Scale (TWSTRS). Resultados: A gravidade da DC (TWSTRS) correlacionou-se moderadamente com duas sub-escalas da SF-36: aspectos físicos $(r=-0,42)$ e dor $(r=-0,43)$. Mulheres apresentaram piores pontuações em duas sub-escalas da SF-36: vitalidade $(p<0,05)$ e saúde mental

Correspondence

Mariana Araújo Ribeiro Queiroz Rua Andirá 195 / 81 86020-520 Londrina PR - Brasil E-mail: marianaqueiroz@usp.br

\section{Conflicts of interest} The authors report no conflicts of interest

Received 18 April 2011 Received in final form 10 June 2011 Accepted 17 June 2011 $(p<0,005)$. Conclusão: Gravidade da DC e gênero (feminino) foram os principais fatores relacionados à pior percepção de QV. Estes achados podem auxiliar profissionais da saúde a identificarem quais características poderiam levar a uma pior QV, e assim direcionar melhor suas intervenções, atenuando os danos causados pela DC.

Palavras-Chave: distonia cervical, qualidade de vida, toxina botulínica do tipo-A, Toronto Western Spasmodic Torticollis Rating Scale, Short-form Health Survey.

'Physical therapist, Movement Disorders Clinic of the Division of Neurology, Hospital das Clínicas of the University of São Paulo School of Medicine, São Paulo SP, Brazil; ${ }^{2}$ Clinical Neurology, Movement Disorders Clinic of the Division of Neurology, Hospital das Clínicas of the University of São Paulo School of Medicine, São Paulo SP, Brazil. 
Cervical dystonia (CD) is the most common form of focal dystonia and its prevalence is estimated to be 11.5 cases per 100,000 individuals ${ }^{1,2}$. CD is characterized by involuntary contractions of cervical region muscles, leading to awkward posture of the head and neck. Most of the cases have idiopathic origin ${ }^{3}$.

The most debilitating symptoms in this condition are: pain, head abnormal posture, and tremor ${ }^{4}$. The pain, present in two third of patients, is the most disabling $o e^{5}$. Mental stress resulting from the disease may also contribute for the high level of dysfunction and interferes in important aspects of daily living such as professional and social activities ${ }^{6}$. Its effect on patient's health is comparable to progressive and generalized neurological degenerative diseases which are more severe than $\mathrm{CD}^{1}$.

Botulinum toxin (BTx) is the most effective treatment option for focal dystonias, which includes CD. It leads to symptoms relief, specially pain, and significant postural improvement ${ }^{7}$. Many studies show improvement of quality of life (QoL) after BTx injections ${ }^{1,8,9}$. Other authors ${ }^{10,11}$, on the other hand, disagree with this point of view since their patients did not have significant improvement of QoL after BTx injections. Some reasons may partially explain these conflicting opinions: the effect of the treatment changes over time reaching a plateau after the injection and decreasing soon after it; not all injections achieve the same results; it is a long-term treatment and the procedure has to be repeated frequently. These facts discourage the patients and leads to negative impact in their QoL.

Although many studies ${ }^{1,8,10,12}$ have demonstrated that CD impacts negatively in the patient's QoL there are no agreements about which individual or social aspects are the most troublesome. Furthermore, there are few data about patients QoL without the effect of BTx treatment or with only residual effects, since in most studies the authors assess the QoL exclusively during the period of action of BTx without an adequate control ${ }^{10}$, or do not even mention when they interviewed their patients ${ }^{1,12}$.

The purpose of the present study was to evaluate QoL in a Brazilian population of individuals with $C D$ without the effect of BTx or with only residual effect of BTx, and identify possible clinical and social aspects that affect their QoL that can be targeted by specific interventions.

\section{METHOD}

Sixty five out of sixty seven consecutive CD patients treated at the Movement Disorder Clinic of the Division of Neurology of the Hospital das Clínicas of the University of São Paulo School of Medicine were initially evaluated by one physiotherapist during the period of November 2007 to September 2009. The patients were assessed by Short-form Health Survey with 36 questions
(SF-36) and the Toronto Western Spasmodic Torticollis Rating Scale (TWSTRS), at the day they would receive $\mathrm{BT} x$ injection, before the procedure. The study was approved by the hospital ethics committee. All patients had signed the informed consent form prior to their inclusion to the study.

The SF-36 health survey questionnaire yields an eight scale profile and they are hypothesized to form two distinct higher-ordered clusters: physical and mental health. The physical health domain comprehends the following items: physical functioning, role-physical, body pain, and general health. The mental health domain measures the following areas: vitality, social functioning, role-emotional, and mental health. The scores range from zero, the lowest possible score, to one hundred, with 100 representing the highest level of functioning possible ${ }^{13}$. The Brazilian SF-36 version was translated and validated by Ciconelli et al. ${ }^{14}$.

The TWSTRS, developed by Consky et al. ${ }^{15}$, is comprised of three different components which are: severity, disability, and pain. This instrument is reliable and combines the scores obtained by the examiner doctor (severity subcale score), and the rating given by the patients (disability and pain subscales). The total score varies from 0 (best state) to 85 (worst state). Each subscale, severity, disability, and pain, may obtain the maximum scores of 35, 30, and 20 respectively. The more severe the disease the higher is the final score. This scale was translated and adapted to Brazilian Portuguese by SekeffSallem et al. ${ }^{16}$ and is in process of validation to Brazilian Portuguese by the same authors.

The following data were also recorded: gender, age, educational attainment, years of disease, time of treatment with BTx, time lag between years of disease and beginning of BTx treatment.

Before receiving BTx injection, all patients were evaluated by at least two neurologists, with experience on Movement Disorders, who administered BTx type-A in the cervical dystonic muscles. We did not have quantitative measurements, such as electromyograph, to assure that the patients had residual effect or no effect of BTx from last procedure. According to our previous study published elsewhere ${ }^{17}$, the mean duration of clinical improvement obtained from BTx in our patients is 13 weeks. It is a practice in our service to reinject them in approximately 20 week interval, when it is assumed that the patient had no more effect of BTx.

The inclusion criteria for the protocol were: [1] disease diagnosed more than two years from the day of the assessment; [2] a stable and good response for at least two previous treatment session of BTx; [3] signature of the informed consent. The exclusion criteria were: [1] any contraindications for the treatment with BTx; [2] 
cognitive impairment. Two patients, from the total 67 evaluated, were excluded from this study because they did not score the cut-off point of the Mini-Mental State Examination, which varied according to educational attainment. For more details on the use of the method for the Brazilian population, see Brucki et al. ${ }^{18}$.

\section{Statistical analysis}

The numerical variables were tested for normal distribution. Mean and standard deviation were used to describe continuous variables with a normal distribution, whereas median and interquartiles (25-75\%) were used for ordinal data and for continuous variables without a normal distribution. Categorical variables were presented in absolute (n) or relative (\%) frequencies. Pearson and Spearman tests were used to calculate the variables correlation. The correlation coefficient was interpreted based on the following criteria: $0 \leq r \leq 0.39$ =weak correlation; $0.40 \leq r \leq 0.69$ =moderate correlation; $r \geq 0.70=$ =strong correlation. To assess the mean differences Student $t$ and Mann-Whitney tests were used for independent samples. The level of significance was set at $\mathrm{p} \leq 0.05$.

\section{RESULTS}

The mean age of the evaluated patients was 49.90 (Standard deviation - $\mathrm{SD} \pm 14.60$ ) and twenty eight patients $(43 \%)$ were male. The educational attainment was based on years of formal education for which the median was 11 years (8-13, first and third quartiles). There were no statistical differences between gender in all other variables evaluated: age (47.86 SD \pm 13.9 for man and 51.54 $\mathrm{SD} \pm 15.09$ for woman, $\mathrm{p}=0.31$ ), educational attainment (median 11 [8-13, first and third quartiles] for man and 11 [8-14, first and third quartiles] for woman, $\mathrm{p}=0.73$ ), duration of disease (median 11.5 [5.25-18, first and third quartiles] for man and 9 [7-16, first and third quartiles] for woman, $\mathrm{p}=0.92$ ), time of treatment (median 5.25 [2.2514.25 , first and third quartiles] for man and 5 [3-11.25, first and third quartiles] for woman, $\mathrm{p}=0.78)$. The median $\mathrm{du}$ ration of disease, in years was 11 (7-16.50, first and third quartiles), the median time of treatment with BTx was 5 years (3-12, first and third quartiles), and the median interval between the onset of the disease and the respective treatment was 3 years (1-8, first and third quartiles).

In relation to the severity of $C D$, assessed by TWSTRS scale the mean score obtained in subscale I (severity) was 16.80 (SD \pm 4.60 ), scale II (disability) 11.20 (SD \pm 5.10$)$, and subscale III (pain) $9.40(\mathrm{SD} \pm 4.40)$. The sum of all domains mean was $37.40(\mathrm{SD} \pm 10.40)$.

The data obtained by the SF-36 assessment were calculated by median and quartiles (25\%-75\%). The following scores were achieved: physical functioning 65 (35-82.50), role-physical 25 (0-75), body pain 51 (31-
Table 1. Correlations between TWSTRS and QoL (SF-36)

\begin{tabular}{lcc}
\hline SF-36 & TWSTRS (sum of domains) & $\mathrm{p}$ \\
\hline Physical functioning & $r=-0.19$ & 0.14 \\
Role-physical & $r=-0.42$ & 0.001 \\
Body pain & $r=-0.43$ & $<0.0001$ \\
General health & $r=-0.12$ & 0.34 \\
Vitality & $r=-0.15$ & 0.22 \\
Social functioning & $r=-0.35$ & 0.04 \\
Role-emotional & $r=-0.21$ & 0.95 \\
Mental health & $r=-0.23$ & 0.72 \\
\hline
\end{tabular}

Correlations: Spearman correlation test. Significance level $p \leq 0.05$. TWSTRS: Toronto Western Spasmodic Torticollis Rating Scale; QoL: Quality of Life.

Table 2. Influence of gender in QoL (SF-36).

\begin{tabular}{lccc}
\hline SF-36 & $\begin{array}{c}\text { Man Md } \\
(25-75 \%)\end{array}$ & $\begin{array}{c}\text { Woman Md } \\
(25-75 \%)\end{array}$ & p \\
\hline $\begin{array}{l}\text { Physical } \\
\text { functioning }\end{array}$ & $64.80(45-88.70)$ & $53.30(35-55)$ & 0.06 \\
Role- physical & $50(0-93.70)$ & $25(0-50)$ & 0.28 \\
Body pain & $54(31-70.20)$ & $42(30-61.50)$ & 0.31 \\
General health & $64.50(39-72)$ & $57(47-67)$ & 0.38 \\
Vitality & $67.50(56.20-75)$ & $48.20(35-60)$ & 0.005 \\
Social functioning & $57.10(37.50-75)$ & $54.50(31.20-75)$ & 0.72 \\
Role emotional & $66.60(33-100)$ & $57.80(0-100)$ & 0.34 \\
Mental health & $70(52-83)$ & $60(32-77)$ & 0.05 \\
\hline
\end{tabular}

Student test. Significance level $p \leq 0.05$. QoL: Quality of Life.

63.50), general health 62 (46-71), vitality 50 (37.5070 ), social functioning 50 (37.50-75), role-emotional 67 (16.50-100), and mental health 68 (44-76).

We observed that the severity of CD (TWSTRS) correlated moderately with the following two SF-36 subscales: Role-physical $(\mathrm{r}=-0.42)$ and Body pain $(r=-0.43)$. The negative correlation suggests the more severe the CD, the worst is the QoL (Table 1).

Age had poor correlation with SF-36 and TWSTRS, the rank was very low $(r=-0.30)$, this means that the variable age does not influence both scales. Relating educational attainment to QoL, we observed a weak correlation between years of school and SF-36 $(\mathrm{r}<0.30)$ but the same was not observed for TWSTRS ( $\mathrm{r}=0.52)$.

There was weak correlation between onset of $\mathrm{CD}$ and SF-36; in relation to duration of treatment there were also weak correlations to all items of SF-36 scale. The difference between the onset of the disease and time to treatment of CD correlated weakly to all SF-36 subscales. The onset and duration of disease did not correlate to TWSTRS $(\mathrm{r}<0.30)$.

We also compared the TWSTRS and SF-36 scales with gender. No statistical difference was observed be- 
tween gender and TWSTRS but women scored worse in two SF-36 subscales which were: vitality and mental health ( $\mathrm{p}=0.05$ and 0.005 respectively) (Table 2 ).

\section{DISCUSSION}

Our study evaluated QoL of CD patients with residual or no effect of BTx, depicting a scenario mostly not described in the literature. The assessment of QoL is recognized as relevant in the evaluation and management of patients with dystonia ${ }^{19}$, for the reason that the identification of possible physical and social aspects which may affect QoL helps to optimize the treatment ${ }^{10}$.

To assess QoL, general perceptual measures are important tools in the treatment of $C D$ patients because sometimes purely functional quantitative scales are not able to detect significant changes achieved by treatments such as BTx, neurological rehabilitation, psychotherapy, and so on ${ }^{20}$. The effect of the multidisciplinary approach on CD may be estimated by means of scales that combine the measurement of motor functions and the impact that the disease has in the patient's daily life activity, emotional and social functioning ${ }^{21}$. As a result, SF-36 health survey scale is a good tool for this evaluation and it is used in many studies for assessing QoL in $\mathrm{CD}^{9,11,12}$.

Although there is a more specific questionnaire to evaluate quality of life of patients with cervical dystonia and blepharospasm, which is the CDQ-24, it was not used in our series because its Brazilian Portuguese version has not yet been validated.

There are three possible limitations in our study. The first one relates to the fact that, even though there was probably no residual effect of the previous BTx injection by the time the patients were evaluated, it may be hard for patients who are on continuous BTx treatment to discriminate their QoL during the weeks when the effect of the drug is waning from the longer period during which they are under its full effect. Another study comparing untreated patients with $\mathrm{CD}$ with those, like our patients, who are not under the active phase of the treatment, would help clarify if there is indeed a difference in their QoL.

The second limitation relates to the absence of information on other treatments that the patients might be following aside from the BTx, like physiotherapy, during the whole treatment period or just to cover the few weeks of the waning effect of the BTx ${ }^{6}$. Such data was not systematically collected in our study, because in empirical observations in our practice we realized that the vast majority of $\mathrm{CD}$ patients did not follow any other treatment. The third limitation is intrinsic to studies of a descriptive design such as ours, we only studied the QoL of patients with differences in the severity of CD disease, but we did not plan a study to compare the QoL of these patients with normal individuals or with patients with other diseases. One of the main reasons for choosing not do to so was the well known difficulty of finding adequate hospital controls to be used in case-control studies ${ }^{22}$.

In agreement with the results of our study, Sgoigseid et al. ${ }^{9}$, found that higher scores of TWSTRS (more severe cases of $\mathrm{CD}$ ) were associated to lower scores in social functioning of SF-36 scale. These authors also reported similar findings and other relevant factor for lower QoL, such as depression, which was not evaluated in our series.

Hilker et al. ${ }^{23}$, and Müller et al. ${ }^{10}$, did not observe correlations between severity of CD and low QoL, but they utilized Tsui scale. This data suggest that mixed scale which take into account both the health care professional and the patient perception (TWSTRS) is more sensible to assess patient status than measurement based on a single point of view rating (Tsui scale).

Camfield et al. ${ }^{1}$ observed a correlation between age and QoL (role-physical), the older the patient the lower the QoL. This finding is expected to occur in the general population but, according to the authors, it was more evident in individuals with CD. Slawek et al. ${ }^{8}$ also described decrease of SF-36 score (role-physical, role-emotional) inversely proportional to patient's age. The data from the present study did not support their findings, this could be due to the fact that its age range was more extreme than ours ${ }^{1}$. Ben-Sholmo et al. ${ }^{12}$ also did not find any correlation between gender, age, educational attainment or social functioning and worsening of QoL.

Meanwhile duration of the disease (in years), duration of the treatment, also in years, and the difference between these two variables, correlated weakly to physical and emotional domains of SF-36 in our series.

Slawek et al. ${ }^{8}$ also reported a decrease in SF-36 score (role-physical and role-emotional) with the increase of age of onset of $\mathrm{CD}$. There was no correlation between SF-36 (and duration of the disease).

Our study also demonstrated that women scored lower QoL than men, mainly in emotional domains. Camfield et al. ${ }^{1}$ observed that QoL scores were lower for women and for those with low educational level. Even though these findings are also observed in the general population, the author noted that a chronic disorder such as CD maximized the trend observed in the general population. Slawek et $\mathrm{al}^{8}{ }^{8}$ also described worse QoL (social functioning) in women, single individuals, and lower income patients.

In conclusion, or data suggest that the QoL perception in a Brazilian sample of patients with CD was worse for female patients and for those with more severe diseases.

These information may help health professionals to predict which characteristics will lead to worse perception of QoL in CD patients; and so they can better target their approach and make right treatment decisions to lessen the burden caused by CD. 


\section{REFERENCES}

1. Camfield L, Ben-Shlomo Y, Warner TT. Impact of cervical dystonia in quality of life. Mov Disord 2002;17:838-841.

2. Jankovic J. Treatment of dystonia. Lancet Neurol 2006;5:864-872.

3. Lowestein DH, Aminoff MJ. The clinical course of spasmodic torticollis. Neurology 1998;38:530-532.

4. Tarsy D, Simon DK. Dystonia. N Engl J Med 2006;355:818-829.

5. Jankovic J, Leder S, Warner D, Schwartz K. Cervical dystonia: clinical findings and associated movement disorders. Neurology 1991;41:1088-1091.

6. Ramdharry G. Case report: physiotherapy cuts the dose of botulinum toxin. Physiother Res Int 2006;11:117-122.

7. Papathanasiou I, MacDonald L, Whurr R, Jahanshahi M. Perceived stigma in spasmodic torticollis. Mov Disord 2001;16:280-285.

8. Slawek J, Friedman A, Potulska A, et al. Factors affecting the health-related quality of life of patients with cervical dystonia and the impact of botulinum toxin type A injections. Functl Neurol 2007;22:95-100.

9. Sgoigsed IM, Malt UF, Roislien J, Kerty I. Determinants and status of quality of life after long-term botulinum toxin therapy for cervical dystonia. Eur J Neurol 2007;14:1129-1137.

10. Müller J, Kemmler G, Wissel J, et al. The impact of blepharospasm and cervical dystonia on health-related quality of life and depression. J Neurol 2002:429:842-846.

11. Gudex CM, Hawthorne MR, Duffey P. Effect of dystonia and botulinum toxin treatment on health-related quality of life. Mov Disord 1998;13:941-946.

12. Ben-Sholmo Y, Camfield L, Warner T. What are the determinants of quality of life in people with cervical dystonia? J Neurol Neurosurg Psychiatry 2002;72:608-614

13. Severo M, Santos AC, Lopes C, Barros H. Reliability and validity in measuring physical and mental health construct of the Portuguese version of MOS SF-36. Acta Med Port 2006:19:281-287.
14. Ciconelli RM, Ferraz MB, Santos W, Meinão I, Marina RQ. Tradução para a língua portuguesa e validação do questionário genérico de avaliação de qualidade de vida SF- 36 (Brasil SF-36). Rev Bras Reumatol 1999;39: 143-150.

15. Consky ES, Basinki A, Belle L, Ranawaya R, Lang AE. The Toronto Western Spasmodic Torticollis Rating Scale (TWSTRS): assessment of validity and inter-rater reliability. Neurology 1990;40 (Suppl 1):S445.

16. Sekeff-Sallem FA, Caramelli P, Barbosa ER. Cross-cultural adaptation of Toronto Western Spasmodic Torticollis Rating Scale (TWSTRS) to Brazilian Portuguese. Arq Neuropsiquiatr 2011;69:316-319.

17. Maia FM, Kanashiro AK, Chien HF, Goncalves LR, Barbosa ER. Clinical changes in cervical dystonia pattern in long-term botulinum toxin treated patients. Parkinsonism Relat Disord 2010;16:8-11.

18. Brucki SM, Nitrini R, Caramelli P, Bertolucci PH, Okamoto IH. Sugestões para o uso do mini-exame do estado mental no Brasil. Arq Neuropsiquiatr 2003;61:777-781.

19. Page D, Butler A, Jahanshani M. Quality of life in focal, segmental and generalized dystonia. Mov Disord 2007;22:341-347.

20. Ebrahim S. Clinical and public health perspectives and applications of health related quality of life measurement. Soc Sci Med 1995;41: 1383- 1394.

21. Guyatt G, Feeny D, Patrick D. Issues in quality-of-life measurement in clinical trials. Control Clin Trials 1991;12 (Suppl 4):S81-S90.

22. Rothman KJ, Greenland S. Case-Control Studies. In Rothman KJ, Greenland S (Eds). Modern Epidemiology, $2^{\text {nd }}$ ed. Philadelphia, Pa: Lippincott, 1998;93-114

23. Hilker R, Schischniaschvili M, Ghaemi M, Jacobs A, Rudolf J. Health related quality of life is improved by botulinum neurotoxin type A in long term treated patients with focal dystonia. J Neurol Neurosurg Psychiatry 2001:71:193-199. 